University of Wollongong

Research Online

Faculty of Engineering and Information

Faculty of Engineering and Information

Sciences - Papers: Part A

Sciences

$1-1-2015$

Grain size effect of thickness/average grain size on mechanical behaviour, fracture mechanism and constitutive model for phosphor bronze foil

Zhi Fang

University of Wollongong, zf548@uowmail.edu.au

Zhengyi Jiang

University of Wollongong, jiang@uow.edu.au

Xiaogang Wang

Taiyuan University of Science and Technology

Cunlong Zhou

Taiyuan University of Science and Technology, zcunlong@163.com

Dongbin Wei

University of Wollongong, dwei@uow.edu.au

See next page for additional authors

Follow this and additional works at: https://ro.uow.edu.au/eispapers

Part of the Engineering Commons, and the Science and Technology Studies Commons

Research Online is the open access institutional repository for the University of Wollongong. For further information contact the UOW Library: research-pubs@uow.edu.au 


\title{
Grain size effect of thickness/average grain size on mechanical behaviour, fracture mechanism and constitutive model for phosphor bronze foil
}

\begin{abstract}
Size effects play a significant role in microforming process, and any dimensional change can have a great impact on materials' mechanical properties. In this paper, the size effects on deformation behaviour and fracture of phosphor foil were investigated in the form of grain size effect: the ratio of materials' thickness (T) to average grain size (D) by micro tensile tests. The ratio was designed to be closed to but larger than, less than and equal to 1 , respectively. The results show that the amount of plastic deformation decreases with the decrease of the ratio of T/D, which indicates that the grain size plays a significant role and grain deformation modes differ when the ratio changes. It is also found that their fractograph reflects different features in terms of micro-dimples and cleavage planes, further demonstrating that when $T / D>1$, its materials have a tendency to fracture ductilely, while materials would like to conduct brittle fracture when T/D
\end{abstract}

\section{Keywords}

model, phosphor, bronze, foil, effect, thickness, grain, average, size, mechanical, behaviour, fracture, mechanism, constitutive

\section{Disciplines \\ Engineering | Science and Technology Studies}

\section{Publication Details}

Fang, Z., Jiang, Z., Wang, X., Zhou, C., Wei, D. \& Liu, X. (2015). Grain size effect of thickness/average grain size on mechanical behaviour, fracture mechanism and constitutive model for phosphor bronze foil. International Journal of Advanced Manufacturing Technology, 79 (9-12), 1905-1914.

\section{Authors}

Zhi Fang, Zhengyi Jiang, Xiaogang Wang, Cunlong Zhou, Dongbin Wei, and Xianghua Liu 

Grain size effect of thickness/average grain size on mechanical behaviour, fracture
mechanism and constitutive model for phosphor bronze foil

\begin{abstract}
In this paper, the size effects on deformation behaviour and fracture of phosphor foil were investigated in terms of the ratio of materials' thickness $(T)$ to average grain size $(D)$ by micro tensile tests. The results show that the amount of plastic deformation decrease with the decrease of the ratio of $T / D$, which indicates that the grain size plays a significant role and grain deformation modes differ when the ratio changes. It is also found that their fractograph reflect different features in terms of micro-dimples and cleavage planes, further demonstrating that when $T / D>1$, its materials have a tendency to fracture ductilely, while materials would like to conduct brittle fracture when $T / D<1$. So the ratio of $T / D$ which is close to 1 can be regards as the divide of ductile fracture and brittle fracture. For $T / D<1$, a new constitutive model is proposed based on the classic composite model. The model's results are compared with the experimental ones and the efficiency of the developed models is verified.
\end{abstract}

Keywords: Size effect; Thickness/average grain size; Plastic deformation; Fractograph; Constitutive model 


\section{Introduction}

There is no doubt that microforming technology has attracted tens of thousands of attentions due to the prevalent usage of its matching products-micro parts. The increasing demand of micro-scale products for high accuracy and high quality has also inspired the development of microforming technology. Although the metal forming in traditional level has been progressed for centuries and a series of classic knowledge and theories have been established systematically by previous researchers, it is common known that these macro-scale processing theories cannot be directly applied in micro-scale world with minaturisation due to size effect [1-3]. When the scaling of specimens downsize to micro-level, the parameters which may not be important in conventional process begin to play a significant role in controlling the accuracy of deformation, in another way, determining the dimensions of processed specimens.

Several researches have been conducted to investigate the size effect in micro deformation behaviours and mechanics. Engle and Eckstein [1] proposed the surface layer model in which the specimen was divided into two portions: interior part and surface layer, to explain the reduction of flow stress in microforming process. Geiger et al. [4] and Vollertsen et al. [2, 5] published papers with respect to micro-forming and carried out a comprehensive review of state of the art of micro-forming technology. Ma et al. [6] researched the size effect on fracture behaviour in deep drawing process. Their results illustrate that limit drawing ratio (LDR) is significantly decreased with grain size. Kals and Eckstein [7] investigated the size effect in tensile tests, air bending and punching of sheet metals by miniaturisation based on similarity theory, and they concluded that the deformation behaviour in micro-punching is strongly different from those in both tensile test and air bending. Further research from Raulea et al. [8] showed that the yield strength is related to the ratio between the grain size and specimen thickness, which was also demonstrated in a planar blanking and bending process. Chan et al. [9] investigated the scatter effect of grain mechanical properties with micro-compression process and proposed a finite element model with consideration of grain size and the scatter effect of flow stress, which provided a basis for understanding and modelling of materials size effect in microforming process. Lu et al. [10] enhanced this modeling by implanting Voronoi tessellation algorithm into pre-processor of finite element software. Moreover, $\mathrm{Xu}$ et al. [11] studied the size effect on deformation behaviour and fracture feature by micro-blanking in terms of the ratios of different blanking clearances to grain size: $C / D>1, C / D \approx 1$ and $C / D<1$, and found out that the ultimate shearing strength reaches an extreme value when blanking clearance to grain size ratio is equal to 1 . Wang et al. [12] investigated the size effect of cavity dimension in coining process. They revealed that the micro-formability is decreased with the increase of the ratio between grain sizes and die cavity width. Gau et al. [13] conducted three points bending to study the correlation between springback amount and $T / D$ (thickness/average grain diameter) ratios. They observed that springback is related to the ratio of sheet thickness to grain size, but all the ratios were larger than 1. Liu et al. [14] developed a constitutive model considering the grain boundary strain hardening. Fu et al. [15] studied the size effect on fracture behavior of the annealed copper foils with different thicknesses and grain sizes by tensile tests, and they found that the number of micro-voids as well as the fracture stress and strain decrease with $T / D$. Hmida et 
al. [16] conducted the single point incremental forming process of copper foils with different grain sizes, and it is observed the formability decreases with $T / D$. However, the materials' the ratios of thickness to grain size $(T / D)$ in these studies are limited to larger than 1 .

In microforming process, the size effect of materials plays a significant role in influencing the deformation results and the accuracy of final products. Nevertheless, it is noticeable that among the prior studies, there is a lack of in-depth research on the interactive effect of micro deformation behaviours and the size effect expressed by the ratios of specimen thickness to grain size, especially when they are approximately larger than, equal to and less than 1 . This means there is just more than one grain, only one grain or an incomplete grain in the thickness direction. In this research, uniaxial tensile tests were carried out with phosphor bronze foil to study the effect of the ratio $T / D$ on micro scale plastic deformation, and their fracture morphologies were observed under Scanning Electron Microscope (SEM). The ratios are reflected as $T / D>1(1.23), T / D<1(0.68)$ and $T / D \approx 1$ (1.07) respectively by means of different annealing treatments. At the same time, with consideration that the surface layer model cannot be applicable when $T / D<1$, a new constitutive model are proposed based on the classic composite model. The model's results are compared with the experimental ones and the efficiency of the developed models is verified. 


\section{Micro tensile experiment}

\subsection{Sample preparation}

Phosphor bronze C5191 foil from cold rolling with thickness $70 \mu \mathrm{m}$ was employed to conduct this research due to its wide application in industries. The chemical compositions of phosphor bronze are displayed in Table 1.

Table 1 Chemical compositions of phosphor bronze C5191, in wt\%.

\begin{tabular}{lllll}
\hline $\mathrm{Sn}$ & $\mathrm{P}$ & $\mathrm{Pb}$ & $\mathrm{Fe}$ & $\mathrm{Zn}$ \\
\hline 5.87 & 0.22 & 0.004 & 0.001 & 0.004 \\
\hline
\end{tabular}

The bending specimens measuring $2 \times 1 \times 0.07 \mathrm{~mm}$ were cut by wire-cut EDM from as-received materials, and then these specimens were subjected to various heat treatments to obtain different grain sizes. To accomplish the aim with scale factor to be greater than, less than and equal to 1 individually, the materials were annealed in Ar air protection condition with different temperatures and holding times before furnace cooling. The anneal conditions are presented in Table 2. The heat-treated specimens were etched using a solution of $5 \mathrm{~g} \mathrm{of} \mathrm{FeCl}_{3}$, $50 \mathrm{ml}$ of $\mathrm{HCl}$ and $100 \mathrm{ml}$ of $\mathrm{H}_{2} \mathrm{O}$ for 1-2 s. The microstructures of three different grain sizes in thickness direction are shown in Fig. 1. It can be seen that the grain size increases with holding time under the same annealing temperature.

Table 2 Heat treatment and average grain size

\begin{tabular}{llll}
\hline Temperature $\left({ }^{\circ} \mathrm{C}\right)$ & 550 & 550 & 550 \\
\hline Time $(\mathrm{h})$ & 4 & 6 & 8 \\
Thickness, $T(\mu \mathrm{m})$ & 70 & 70 & 70 \\
Average grain size, $D(\mu \mathrm{m})$ & 57.1 & 65.7 & 103.4 \\
$T / D$ & 1.23 & 1.07 & 0.68 \\
\hline
\end{tabular}
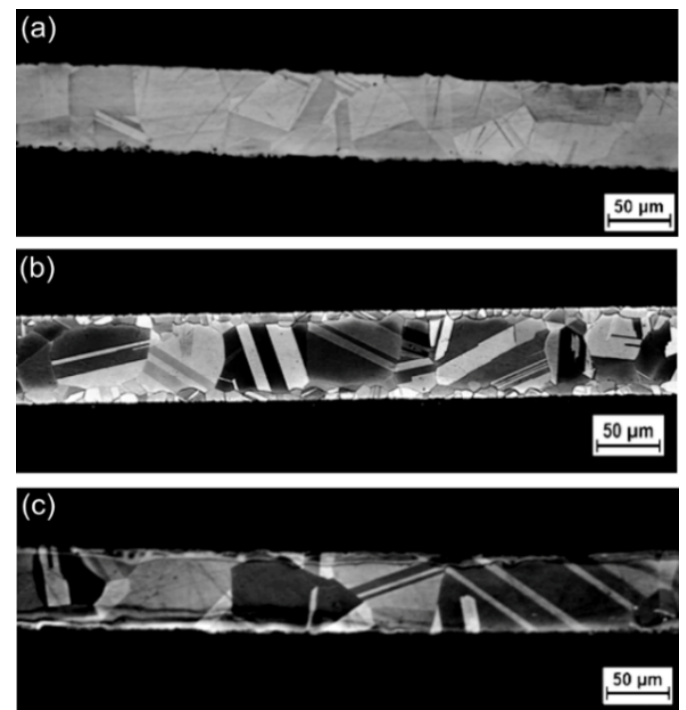

Fig. 1. Microstructure of annealed phosphor bronze foil. (a) $T=70 \mu \mathrm{m}, D=57.1 \mu \mathrm{m}, T / D<1$; (b) $T=70 \mu \mathrm{m}, D=65.7 \mu \mathrm{m}$, $T / D \approx 1$; (c) $T=70 \mu \mathrm{m}, D=103.1 \mu \mathrm{m}, T / D<1$ 


\subsection{Micro tensile test}

To further investigate the mechanical properties of these materials which are equipped with different $T / D$ ratios, micro tensile tests were conducted. The dimensions of tensile specimens can be seen in Fig. 2. The tensile specimens were also annealed under the above heat treatment process. The tests were conducted on Instron micro tester 5848 as shown in Fig. 3. A video extensometer was utilised to record and measure the strain precisely. The crosshead velocity was $0.02 \mathrm{~mm} / \mathrm{s}$ for all the tests, and each test was repeated three times.

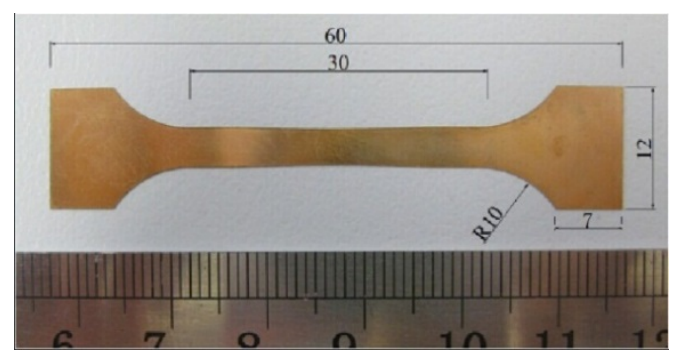

Fig. 2. The tensile test specimen.

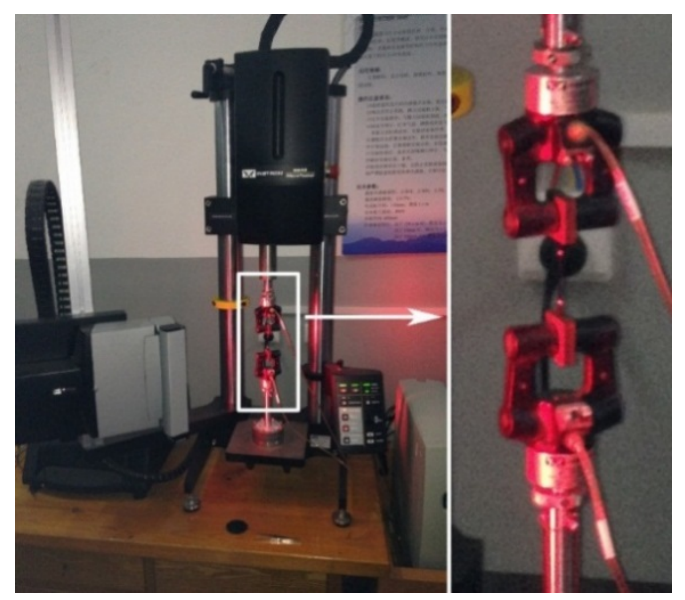

Fig. 3. Instron micro tester 5848 with video extensometer. 


\section{Results and discursion}

\subsection{The effect of $T / D$ on stress-strain curves}

It can be seen from Fig. 4 that materials' plasticity increase with the increase of their ratios of $T / D$, while the scatter of stress-strain curves profile decreases. When $T / D<1$, the average grain size is larger than specimen's thickness, which means most grains involved in the tensile specimens are incomplete. Consequently, due to the lack of grain boundaries and grain boundary corners, concentrated plastic deformation is very difficult to be initiated [17]. This can explain that tensile tests in this group hardly experience plastic deformation. Furthermore, it is clear that this ratio's scatter of stress-strain curves is most obvious in these three groups shown in Fig. 4(a). This is because without the limitation of grain boundaries, the grain crystal orientation varies and the sliding systems are oriented distinctively when starting an applied stress. In addition, some other deformation modes, such as grain rotation and coordination could change the grain deformation behaviors. Therefore, this kind of grain heterogeneity can contribute to the irreproducible strain-stress relationships. When $T / D>1$, the specimen materials can be regarded as polycrystalline aggregate. The quantity of grain boundaries and grain boundary corners will increase largely, which will lead to the appearance of work-hardened grain boundary layers [18]. Once these layers are formed, the stresses within the polycrystalline aggregate will homogenise. The deformation normally take place with the most favorable grain sliding systems, thus the strain-stress curves obtained from this group are the most reproducible which is reflected in Fig. 4(c). At the same time, due to the large number of dislocations pile up at grain boundaries and their corners, there is great tendency to activate the plastic deformation, so materials with the ratio $T / D>1$ have the best plasticity comparing to the other two. When $T / D \approx 1$, it is notable in Fig. 4(b) that stress-strain curves are repeated roughly. In this case, there is only one grain in the thickness direction, thus grain matrix deformation and grain boundary sliding can be dominant simultaneously during tests [11]. Plastic deformation is relatively easy to happen because there are grain boundary corners gathering near two sides of thickness direction. However, due to the limitation from thickness direction, grain orientation and coordination cannot occur as easily as they are comparing to materials with $T / D>1$. Therefore, this uncertainty can attribute to the slight scatter of stress-strain curves. According to the results from tensile tests, it is found when the ratio of thickness to grain size is small enough (around 1), the strain-stress relationship on one hand is consistent with classic Hall-Petch relationship as long as average grain size is not scaling down to $10 \mathrm{~nm}$ [19]. On the other hand, it becomes very sensitive to the value of the ratio of thickness to average grain size, especially when comparing the plastic deformation occurred with materials' $T / D>1$ to $T / D<1$. 


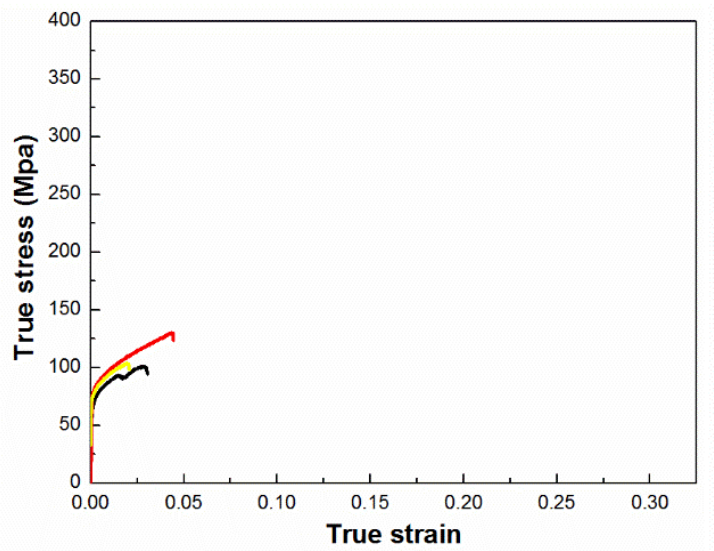

(a)

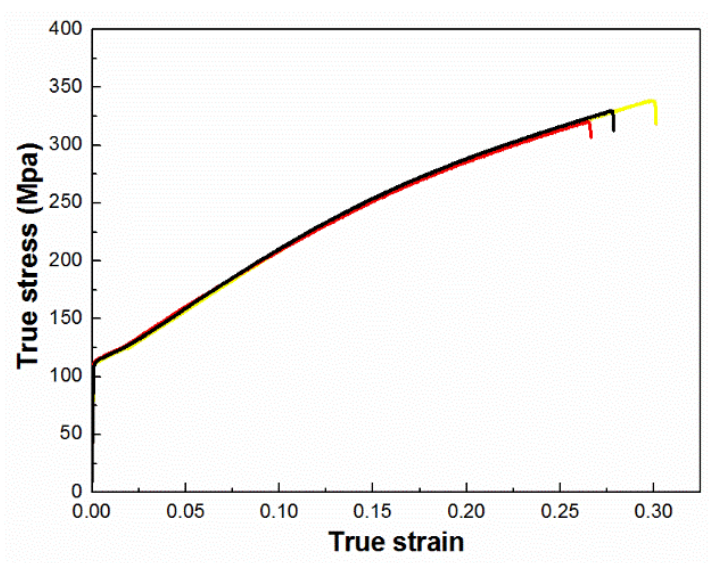

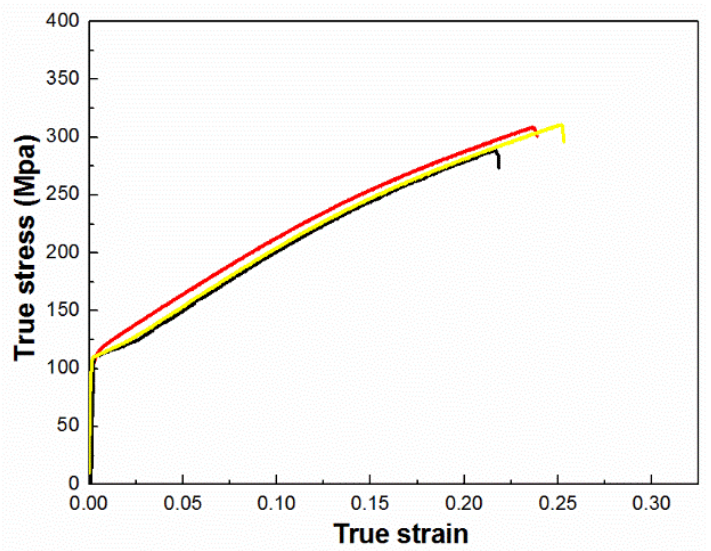

(b)

(c)

Fig. 4. Strain-stress curves when different $T / D$ ratios: (a) $T / D<1$, (b) $T / D \approx 1$, (c) $T / D>1$.

\subsection{The effect of $T / D$ on fracture behaviour}

The fractograph of the tensile-tested samples are shown in Fig. 5. It is noticeable that different fractograph images were obtained with different ratios of thickness to average grain size. It is found that the number of micro-dimples decreases with the decreasing $T / D$. This is consistent with prior studies [15]. The grain boundary fraction in the materials increase with the value of $T / D$ and because the grain boundaries act as obstacles to dislocation motion, the stresses concentrate at or near grain boundary regions and cause micro-voids and micro-dimples formation consequently in the deformation process. At the same time, micro-dimples and cleavage planes can be found together in all three fractograph, which shows materials can have the mixture of ductile fracture mode and brittle fracture mode, indicating partial plastic deformation occurred during tensile testing. However, a difference can be observed on the fracture surface that the micro-dimples generated when $T / D>1$ is averagely distributed along fracture direction, while when $T / D \approx 1$ micro-dimples are mainly focused on a certain limited area, and only a few micro-dimples can be found when $T / D<1$. This phenomenon shows that when more one grain exist in thickness direction, its materials' plasticity is better than that of materials which has just one grain or incomplete one in thickness direction. Inversely, when the ratios of $T / D$ decrease from larger than 1 to less than 
1 , the number of the cleavage planes increase gradually. When $T / D<1$, cleavage planes take up almost the whole area of fracture surface. This dramatic change can be explained when the grain size approaches to, even overpass the thickness value, the location, size and the orientation of each grain affect the fracture behaviour significantly. With the decrease of the ratio $T / D$, the quantity of the grain boundaries will also decrease, which means when only incomplete grains exist in thickness direction, it forces the grains to have an extremely unfavorable orientation towards the tensile direction, leading to a strong tendency of brittle fracture.
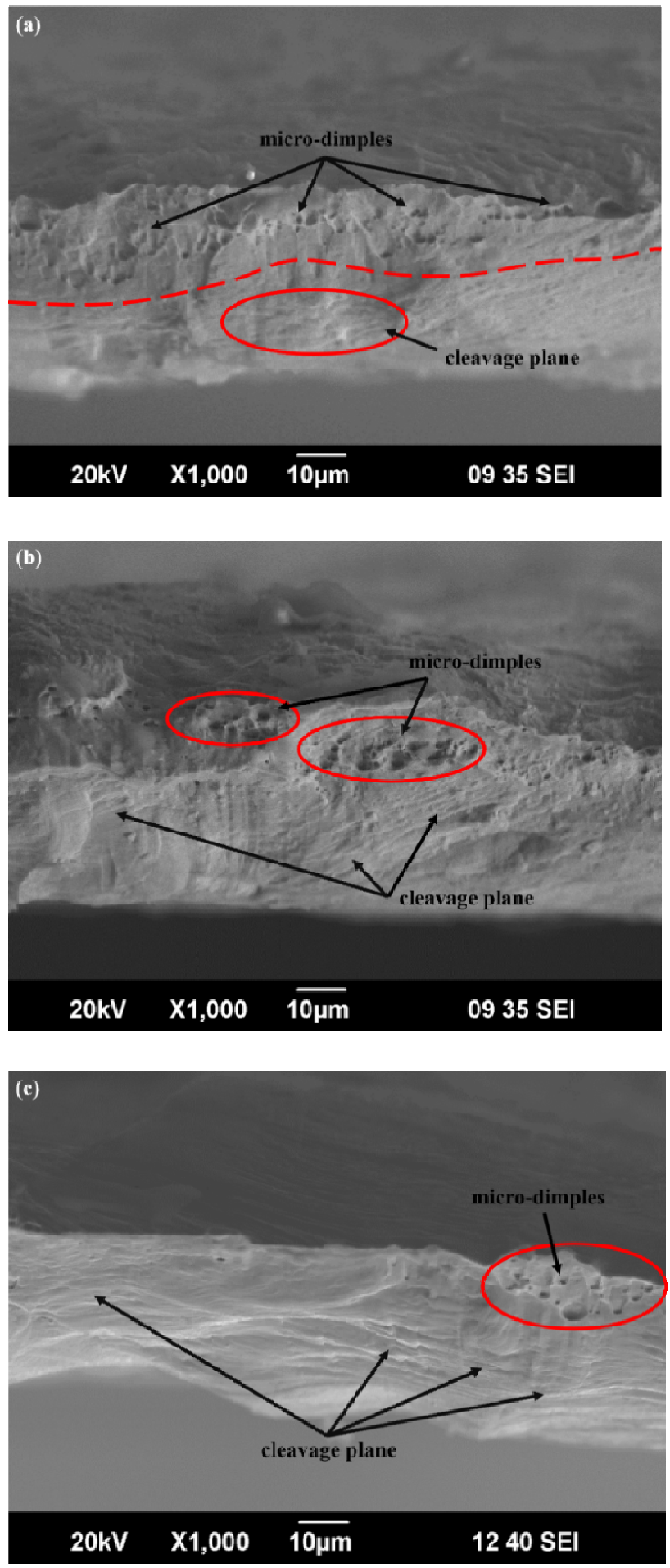
Fig. 5. Fracture morphology of tested samples. (a) $T / D>1$, (b) $T / D \approx 1$, (c) $T / D<1$.

\section{Constitutive model}

When the ratio of $T / D$ is larger than 1, there are generally at least one complete grains in thickness direction. So the material can be regarded as two portions: inner portion and surface layer. One grain can be taken as the inner portion of the material, and the other portion can be treated as surface layer. In this way, the classic surface layer model can still be applicable when the ratio of $T / D$ is between 1 and 2 . The flow stress of the material is expressed as the weighted average of the inner portion' stresses and the surface layer's stresses as follows:

$$
\sigma=\eta \sigma_{\text {inner }}+(1-\eta) \sigma_{\text {surf }}
$$

where $\sigma$ is the flow stress of the material, $\sigma_{\text {inner }}$ and $\sigma_{\text {surf }}$ are the stresses of the inner portion and the surface layer of the material respectively. $\eta$ is size factor to express the fraction of inner portion to the whole material area. It can be calculated based on the following equation [20].

$\eta=\frac{T-D}{T}$

It is notable that this equation cannot be applied when $T<D(T / D<1)$, which means the grain size is larger than the strip thickness, and only incomplete grains can be observed from the cross section of material. Unlike the previous assumption [14] that the flow stress of surface layer is equal to that of grain interior, the grain boundary strengthening effect cannot be neglected in these two circumstances due to the limited quantities of grain boundaries. Since there is no good way to divide these structures into two portions just like the classic surface layer model, a new constitutive model is proposed in order to better describe these particular material size effects.

The methodology of studying grain size effect on flow stress is based on the composite model developed by Kocks [21] and Meyers and Ashworth [18]. This model has been proven to be a valid and effective approach to describe the relationship between the flow stress of polycrystalline aggregate and grain size. This composite model assumes that grains are spherical and are composed of grain boundary layers and grain interiors, which is illustrated in Fig. 6. The idealised representation of the aggregate for $T / D<1$ is shown in Fig. 7 and the flow stress of the grain aggregate can be expressed as:

$$
\sigma_{y}=A_{G} \sigma_{f G}+A_{G B} \sigma_{f G B}
$$

$A_{G}$ and $A_{G B}$ are the areal fractions of grain interior and grain boundary respectively. With average grain size $D$ and material thickness $T$, the grain boundary layers are assumed to have a thickness $t$. 


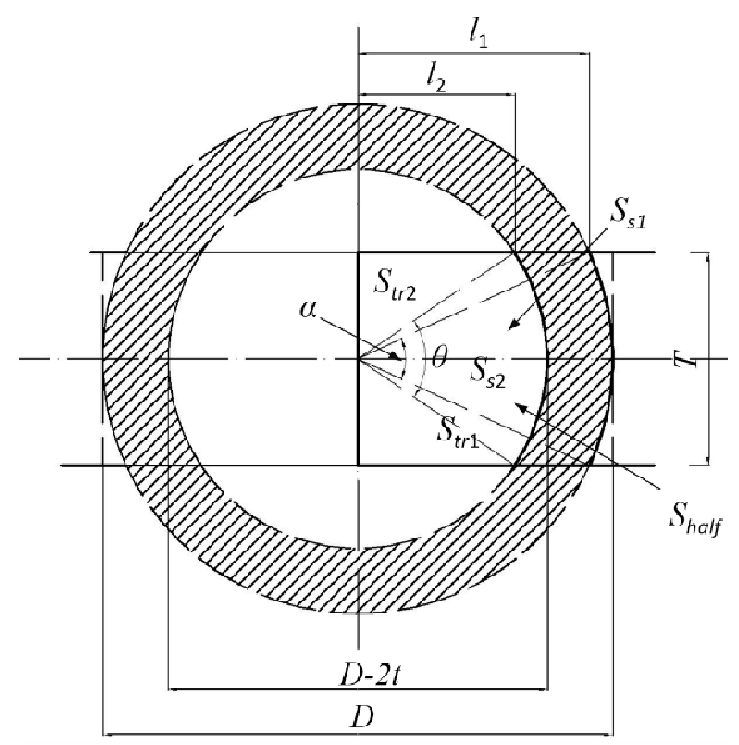

Fig. 6. Schematic of proportions of grain interior and grain boundary.

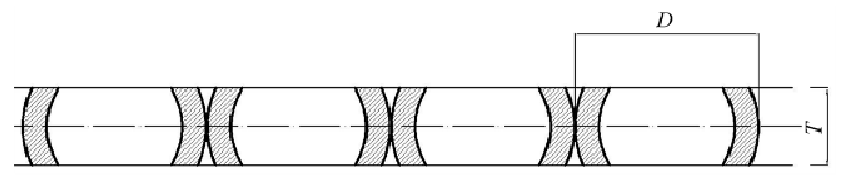

Fig. 7. Ideal aggregate viewed as composite materials with single incomplete grain in thickness direction.

As it can be seen from Fig. 6, an idealised spherical grain is limited in thickness direction, and the proportion of grain interior and grain boundary is decided by the thickness value of the material and average grain size, which can be quantified as the ratio of T/D. Taking left half grain as an example, the areal fractions are expressed by:

where denotes the area of left half rectangular, and area consists of one sector and two triangles. Similarly, area is made up of one sector and two triangles , and the extra part of the rectangular is treated as grain interior.

The two sectors and can be calculated respectively as: 


$$
\begin{gathered}
S_{S 1}=\frac{\theta \pi\left(\frac{D}{2}\right)^{2}}{360} \\
S_{S 2}=\frac{\alpha \pi\left(\frac{D}{2}-t\right)^{2}}{360}
\end{gathered}
$$

where $\theta$ is the central angle for $S_{S 1}$, and $\alpha$ is the central angle for $S_{s 2}$. They are expressed based on law of cosines by:

$$
\begin{gathered}
\theta=\cos ^{-1}\left[\frac{2\left(\frac{D}{2}\right)^{2}-T^{2}}{2\left(\frac{D}{2}\right)^{2}}\right] \\
\alpha=\cos ^{-1}\left[\frac{2\left(\frac{D}{2}-t\right)^{2}-T^{2}}{2\left(\frac{D}{2}-t\right)^{2}}\right]
\end{gathered}
$$

To calculated the areas of triangles $S_{t r 1}$ and $S_{t r 2}$, values of $l_{1}$ and $l_{2}$ need to be obtained. The relationship between the central angles and $l_{1}, l_{2}$ are:

$$
\begin{aligned}
& l_{1}^{2}=\left(\frac{D}{2}\right)^{2}-\left(\frac{T}{2}\right)^{2} \\
& l_{2}^{2}=\left(\frac{D}{2}-t\right)^{2}-\left(\frac{T}{2}\right)^{2}
\end{aligned}
$$

Therefore, the triangles' area can be calculated by:

$$
\begin{aligned}
& s_{t r 1}=\frac{1}{2} \frac{T}{2} l_{1} \\
& s_{t r 2}=\frac{1}{2} \frac{T}{2} l_{2}
\end{aligned}
$$

Rearranging above equations, the areal fraction of grain boundary and grain interior can be expressed respectively:

$$
\begin{aligned}
& A_{G}=\frac{\pi\left\{D^{2} \cdot \cos ^{-1}\left(1-2 T^{2} D^{-2}\right)-(D-2 t)^{2} \cdot \cos ^{-1}\left[1-2 T^{2}(D-2 t)^{-2}\right]\right\}+360 T\left[\sqrt{D^{2}-T^{2}}-\sqrt{(D-2 t)^{2}-T^{2}}\right]}{T \cdot D / 2} \\
& A_{G B}=1-\frac{\pi\left\{D^{2} \cdot \cos ^{-1}\left(1-2 T^{2} D^{-2}\right)-(D-2 t)^{2} \cdot \cos ^{-1}\left[1-2 T^{2}(D-2 t)^{-2}\right]\right\}+360 T\left[\sqrt{D^{2}-T^{2}}-\sqrt{(D-2 t)^{2}-T^{2}}\right]}{T \cdot D / 2}
\end{aligned}
$$

Substituting Equations (17) and (18) into Equation (3), then the new constitutive model the can be expressed by:

$$
\begin{aligned}
& \sigma_{y}=\sigma_{f G} \cdot \frac{\pi\left\{D^{2} \cdot \cos ^{-1}\left(1-2 T^{2} D^{-2}\right)-(D-2 t)^{2} \cdot \cos ^{-1}\left[1-2 T^{2}(D-2 t)^{-2}\right]\right\}+360 T\left[\sqrt{D^{2}-T^{2}}-\sqrt{(D-2 t)^{2}-T^{2}}\right]}{T \cdot D / 2} \\
& +\sigma_{f G B}\left\{1-\frac{\pi\left\{D^{2} \cdot \cos ^{-1}\left(1-2 T^{2} D^{-2}\right)-(D-2 t)^{2} \cdot \cos ^{-1}\left[1-2 T^{2}(D-2 t)^{-2}\right]\right\}+360 T\left[\sqrt{D^{2}-T^{2}}-\sqrt{(D-2 t)^{2}-T^{2}}\right]}{T \cdot D / 2}\right\}
\end{aligned}
$$

According to the previous studies [17], the relationship between average grain size $D$ and the thickness of grain boundary for copper and copper alloys $t$ was:

$t=0.133 D^{0.7}$ 
The flow stresses of grain interior and grain boundary of copper alloy is determined in the reference [14] shown in Fig. 8. It can be seen that the grain boundaries show a much faster rising hardening rate comparing to the gran interiors. This phenomenon has been exemplified by the results in the research of Hirth [22]. The grain-boundary regions are shown with pronounced slip activity on two slip systems, which leads to a much higher hardening rate than the grain interiors. Fig. 9 shows the comparison of the calculated and the experimental true stress-strain curves which were obtained under the condition of specimens' $T / D>1$. A good agreement between the calculations and experiments [23] illustrates that the developed constitutive model is capable to predict the relationship between stress and strain when the value of materials' thickness/average grain size is less than 1 which can be often seen in microforming.

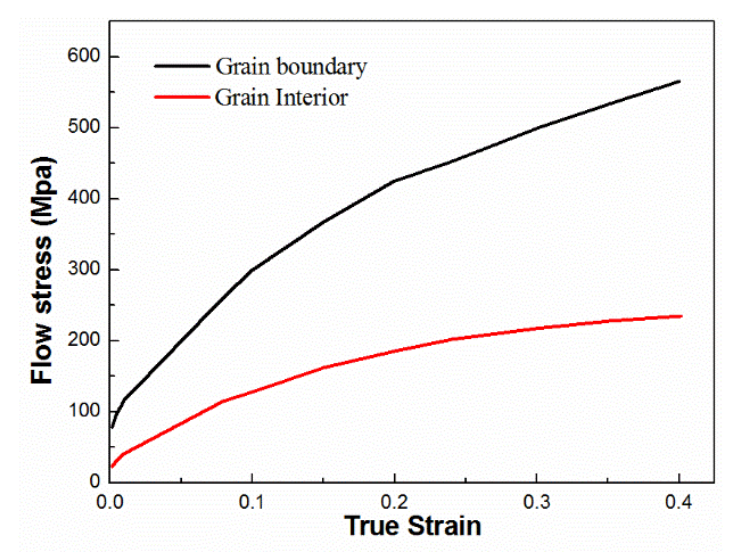

Fig. 8. Flow stresses of grain interior and boundary of pure copper and copper alloy sheet foil.

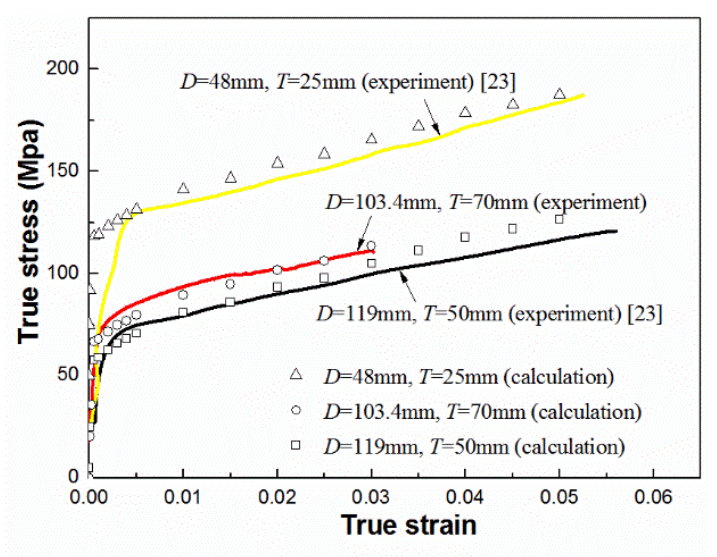

Fig. 9. Comparison of calculated and experimental stress-strain curves when $T / D<1$. 


\section{Conclusions}

In this paper, the influence of the ratio of thickness to average grain size on materials' deformation and fracture behaviour was investigated. The ratios were chosen to be around 1 , but in three different fields: $T / D>1$ (1.23), $T / D \approx 1$ (1.07) and $T / D<1$ (0.68). The following conclusions are obtained:

(1) Plastic deformation increase with the increase of $T / D$, and this is extremely obvious when comparing the plastic deformation occurred with materials' $T / D<1$ to $T / D>1$. This shows that deformation behaviour is very sensitive to the value of the ratio of thickness to average grain size when the range is around 1 .

(2) The number of micro-dimples decreases with the decrease of $T / D$, while the number of cleavage planes increase with it. When $T / D>1$, micro-dimple can be found are averagely distributed in fracture surface, which shows a great tendency of ductile fracture. However, large area of cleavage plane means that brittle facture has a strong tendency to be occurred when $T / D<1$. Therefore, $T / D \approx 1$ can be regards as the divide of ductile fracture and brittle fracture, and this ratio becomes a decisive factor to materials' fracture mode.

(3) When $T / D<1$, there is only single incomplete grain in thickness direction, and classic surface layer model cannot be applied in this situation. A new constitutive model is developed based on composite model with the consideration of $T / D<1$. Comparison was made between simulation values and experimental ones, and a good agreement verified the validity of the developed model.

\section{Acknowledgements}

The authors would like to thank the Australia Research Council (ARC) and Chinese scholarship council (CSC) for their finical support.

\section{References}

[1] U. Engel, R. Eckstein, Microforming-from basic research to its realization, Journal of Materials Processing Technology, 125 (2002) 35-44.

[2] F. Vollertsen, D. Biermann, H.N. Hansen, I. Jawahir, K. Kuzman, Size effects in manufacturing of metallic components, CIRP Annals-Manufacturing Technology, 58 (2009) 566-587.

[3] W. Chan, M. Fu, J. Lu, The size effect on micro deformation behaviour in micro-scale plastic deformation, Materials \& Design, 32 (2011) 198-206.

[4] M. Geiger, M. Kleiner, R. Eckstein, N. Tiesler, U. Engel, Microforming, CIRP Annals-Manufacturing Technology, 50 (2001) 445-462.

[5] F. Vollertsen, H. Schulze Niehoff, Z. Hu, State of the art in micro forming, International Journal of Machine Tools and Manufacture, 46 (2006) 1172-1179.

[6] X. Ma, R. Lapovok, C. Gu, A. Molotnikov, Y. Estrin, E. Pereloma, C. Davies, P. Hodgson, Deep drawing behaviour of ultrafine grained copper: modelling and experiment, Journal of materials science, 44 (2009) 3807-3812. 
[7] T. Kals, R. Eckstein, Miniaturization in sheet metal working, Journal of Materials Processing Technology, 103 (2000) 95-101.

[8] L. Raulea, A. Goijaerts, L. Govaert, F. Baaijens, Size effects in the processing of thin metal sheets, Journal of Materials Processing Technology, 115 (2001) 44-48.

[9] W. Chan, M. Fu, J. Lu, J. Liu, Modeling of grain size effect on micro deformation behavior in micro-forming of pure copper, Materials Science and Engineering: A, 527 (2010) 6638-6648.

[10] H. Lu, D. Wei, Z. Jiang, X. Liu, K. Manabe, Modelling of size effects in microforming process with consideration of grained heterogeneity, Computational Materials Science, 77 (2013) 44-52.

[11] J. Xu, B. Guo, C. Wang, D. Shan, Blanking clearance and grain size effects on micro deformation behavior and fracture in micro-blanking of brass foil, International Journal of Machine Tools and Manufacture, 60 (2012) 27-34.

[12] C. Wang, D. Shan, J. Zhou, B. Guo, L. Sun, Size effects of the cavity dimension on the microforming ability during coining process, Journal of Materials Processing Technology, 187 (2007) 256-259.

[13] J.-T. Gau, C. Principe, M. Yu, Springback behavior of brass in micro sheet forming, Journal of Materials Processing Technology, 191 (2007) 7-10.

[14] J. Liu, M. Fu, J. Lu, W. Chan, Influence of size effect on the springback of sheet metal foils in micro-bending, Computational Materials Science, 50 (2011) 2604-2614.

[15] M. Fu, W. Chan, Geometry and grain size effects on the fracture behavior of sheet metal in micro-scale plastic deformation, Materials \& Design, 32 (2011) 4738-4746.

[16] R. Ben Hmida, S. Thibaud, A. Gilbin, F. Richard, Influence of the initial grain size in single point incremental forming process for thin sheets metal and microparts: Experimental investigations, Materials \& Design, 45 (2013) 155-165.

[17] H.-H. Fu, D.J. Benson, M.A. Meyers, Analytical and computational description of effect of grain size on yield stress of metals, Acta Materialia, 49 (2001) 2567-2582.

[18] M.A. Meyersm, E. Ashworth, A model for the effect of grain size on the yield stress of metals, Philosophical Magazine A, 46 (1982) 737-759.

[19] J. Schiøtz, F.D. Di Tolla, K.W. Jacobsen, Softening of nanocrystalline metals at very small grain sizes, Nature, 391 (1998) 561-563.

[20] X. Lai, L. Peng, P. Hu, S. Lan, J. Ni, Material behavior modelling in micro/meso-scale forming process with considering size/scale effects, Computational Materials Science, 43 (2008) 1003-1009.

[21] U. Kocks, The relation between polycrystal deformation and single-crystal deformation, Metallurgical and Materials Transactions, 1 (1970) 1121-1143.

[22] J.P. Hirth, The influence of grain boundaries on mechanical properties, Metallurgical Transactions, 3 (1972) 3047-3067.

[23] H.-z. Li, X.-h. Dong, Y. Shen, R. Zhou, A. Diehl, H. Hagenah, U. Engel, M. Merklein, J. Cao, Analysis of microbending of CuZn37 brass foils based on strain gradient hardening models, Journal of Materials Processing Technology, 212 (2012) 653-661. 